\title{
Spatial working memory as ancedent fluid reasoning capacity
}

\section{Burdukova*Y., Alekseeva** O., Rzhanova** I. \\ *Moscow State University of Psychology and Eduction, ** FGBNU "Psychological Institute of Russian Academy of Education}

One of the central problems for the studies of individual differences is relationship between fluid intelligence and partial cognitive functions. Significant relationships exist between general fluid intelligence and each of the following constructs: short-term visual recognition memory, working memory capacity and processing speed (Duncan, 2005; Ferrer et al., 2009). The main research interest is focused on connection of fluid intelligence with working memory function, as one of the most important Executive functions. For the last ten years in cognitive science increased number of studies, demonstrating the relationship between working memory and fluid intelligence [Fry, Hale, 2000; Conway et al., 2002; Kane et al., 2004] The objective of this work is to investigate the relation between fluid intelligence and partial cognitive functions, including working memory capacity (WMC). Such type of research is for the first time carried in Russian language.

\section{Subjects}

A total sample of 60 Russian boys and girls aged between 5 years and 5 month and 17 years and 8 month were examined in the study. The sample consist of 32 boys aged from 6 years 4 months to 17 years 3 months and 28 girls aged from 5 years old rsc5 months to 17 years 8 months. All children were students of mass schools, or attended kindergarten. The average age in the groups was equalized (see Table 1).
Materials and Methods

1. To estimate fluid intelligence we used Kaufman Assessment Battery for Children, second edition (KABC-II) (Kaufman, Kaufman et al., 2004). Fluid intelligence scale is based on Story completion and Pattern reasoning subtests.

Table 1. Mean and standard deviation of children age

\begin{tabular}{|c|c|c|c|}
\hline $\begin{array}{c}\text { Age of } \\
\text { Testing }\end{array}$ & $\begin{array}{c}\text { All } \\
\text { sample } \\
(\mathrm{M} \pm \mathrm{SD})\end{array}$ & $\begin{array}{c}\text { Boys } \\
(\mathrm{M} \pm \mathrm{SD})\end{array}$ & $\begin{array}{c}\text { Girls } \\
(\mathrm{M} \pm \mathrm{SD})\end{array}$ \\
\hline KABC-II & $12.8 \pm 3.2$ & $13.3 \pm 2.6$ & $12.3 \pm 3.7$ \\
\hline CANTAB & $13.3 \pm 3.2$ & $13.7 \pm 2.6$ & $12.9 \pm 3.6$ \\
\hline
\end{tabular}

2. We using CANTABeclipse for assessment partial cognitive functions. Tests from CANTABeclipse:

-Spatial working memory (SWM) and Stockings of Cambridge (SOC) (planning) for executive functions

-Delayed matching to sample (DMS) and Pattern recognition memory (PRM) for short time visual memory

- Simple reaction time (SRT) and Choice reaction time (CRT) for processing speed.
Results

It was found out strong interrelations between Gf scale, Story Completion scores and SWM error scores, but not between Pattern Reasoning scores and SWM error scores (see Table 2). Correlation for Gf scale and SWM error scores: $r=-0.33, p=0.01$; correlation for Story Completion scores and SWM error scores: $r=-0.33, p=0.03$, but not the "Pattern reasoning" subtest ( $p>0.2$ ). Meanwhile success scores of the "Pattern reasoning" subtest contribute to assessment of general intelligence $(r=$ $0.54, p<0.01$. It was found out strong interrelations between Gf scale scores and SWM error scores. The regression model for Fluid Reasoning Scale was significant $(F=6.85, p=0.01)$ and explained almost $14.3 \%$ of the dispersion. But only spatial working memory scores significantly affected on the dependent variable.

Table 2. Correlations between Fluid Reasoning and Spatial memory

\begin{tabular}{|c|c|c|c|}
\hline SWM & Gf & $\begin{array}{c}\text { Story } \\
\text { Completion }\end{array}$ & $\begin{array}{c}\text { Pattern } \\
\text { Reasoning }\end{array}$ \\
\hline $\begin{array}{c}\text { SWM } \\
\text { Errors }\end{array}$ & $-0.33^{*}$ & $-0.33^{*}$ & -0.16 \\
\hline
\end{tabular}

$* p<0.05$
Other predictors such as processing speed (Simple reaction time and Choice reaction time), short-term memory (Delayed matching to sample and Pattern recognition memory) and planning functions (Stockings of Cambridge) have no relations with Fluid reasoning.

\section{Summary}

According to our data obtained on Russian sample, subtests constituting Fluid intelligence scale of KABC-II are differently connected to other subtests and scales.

This work was supported by grant RFBR № 18-013-01179

\section{References}

Duncan J. Frontal lobe function and general intelligence: why it matters. 2005, 41(2), 215-217. dx.doi.org/10.1016/50010-9452(08)70896-7

Duncan J., Burgess P., Emslie H. Fluid intelligence after frontal lobe lesions. Neuropsychologia 1995, 33, 261-268. doi.org/10.1016/0028-3932(94)/00124-8 anristof, K., Prabhakaran, V., Dorfman, J., Z Zao, Z., Kroger, J. K., Holyoak, K. J. and Gabrieli, J. D. Rostrolateral prefrontal cortex involvement in relationa
integration during reasoning. Neuroimage 2001, 14, 1136-1149, doi.org/10.1006/nimg.2001.0922

Kroger J.K., Sabb F.W., Fales C.L., Bookheimer S.Y., Cohen M.S., Holyoak K.J. Recruitment of anterior dorsolateral prefrontal cortex in human reasoning: parametric study of relational complexity. Cerebral Cortex 2002, 12, 477-485.
doi.org/10.1093/cercor/122.5.477

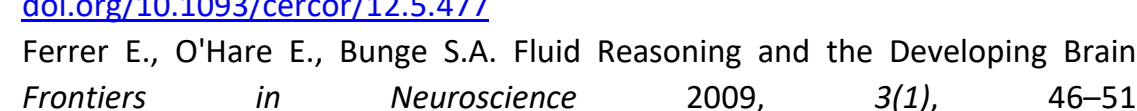
doi.org/10.3389/neuro.01.003.2009

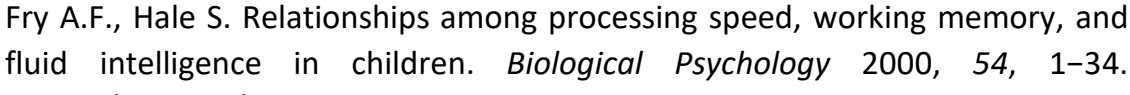
doi.org/10.1016/50301-0511(00)00051-X

variable analysis of working memory capacity, D.J., Minkoff S.R.B. A laten

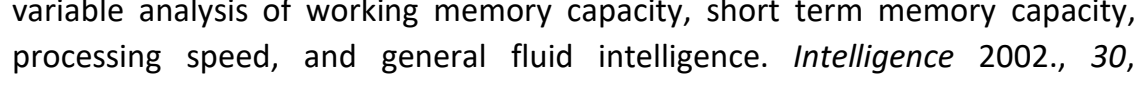
163-183. doi:10.1016/50160-2896(101)00096-4.

Kane M..., Hambrick D.L., Tuholski S.W., Whelm O., Payne T.W., Engle R.W. The generality of working memory capacity: A latentvariable approach to verba Psychology: General 2004, 133(2), 189-217. dx.doi.org/10.1037/00963445.133.2.189

Kaufman A.S., Kaufman N.L. Kaufman Assessment Battery for Children. Second edition. Circle Pines, MN: American Guidance Service, 2004. 